\section{LAS CANCIONES DE HANNS \\ EISLER: LUCHA, EXILIO Y AUTONOMÍA DEL ARTE}

\author{
Sonia Arribas \\ Investigadora ICREA \\ Universidad Pompeu Fabra \\ C/ Ramon Trias Fargas, 25-27 - 08005 Barcelona \\ arribas1234@yahoo.es
}

\section{HANS EISLER'S SONGS: STRUGGLE, EXILE AND AUTONOMY OF ART}

\begin{abstract}
This article describes and analyzes the techniques and lyrics employed by Hanns Eisler in some of the songs he composed during the Weimar Republic and later on during his exile in the United States. If the early compositions were created with the aim of contributing to the workers' political struggle and thus reflect Eisler's rejection of the autonomy of art, or art for its own sake, the later ones can be interpreted as symptoms of what I here call the "forced" autonomy of art.
\end{abstract}

KEY WORDS: Eisler; Weimar Republic; exile; politics; songs; autonomy of art.

\section{INTRODUCCIÓN}

El exilio de Hanns Eisler significó un cambio radical en las condiciones de producción de su música, y en la función social que el compositor pudo encomendarle a sus obras, a sus canciones. Todo lo que había gestado en un período convulso de lucha social y apoyo decidido a los movimientos de trabajadores fue llevado al traste en cuestión de pocos meses, tras la llegada al poder de Hitler.

Eisler fue un medio-judío y comunista que tuvo que venderse (en sus palabras) a la industria cultural norteamericana para sobrevivir en medio de innumerables problemas económicos. El aislamiento y la producción a toda marcha para los estudios de Hollywood fueron determinantes en la elaboración de mecanismos nuevos de composición, derivados de las nuevas condiciones. Los heterogéneos resultados de esta profunda transformación compositiva se constituyen como un crisol expresivo de la situación peculiar que le tocó vivir, de la brecha histórica que cruzó en poco tiempo: no sólo vivió en sus carnes el final del desmoronamiento de cierta cultura europea, de cierta
RESUMEN: En este artículo se describen y analizan las técnicas y letras empleadas por Hanns Eisler en algunas de las canciones que compuso durante la República de Weimar y posteriormente durante su exilio en los Estados Unidos. Si las primeras composiciones fueron creadas con el objetivo de contribuir a la lucha política de los trabajadores y por tanto reflejan el rechazo de Eisler a la autonomía del arte, 0 al arte como un fin en sí mismo, las últimas pueden ser interpretadas como sintomas de lo que aquí denomino la autonomía "forzada" del arte.

PALABRAS CLAVE: Eisler; República de Weimar; exilio; política; canciones; autonomía del arte.

burguesía e ilustración liberal, con el agitado intermedio de la República de Weimar y el surgimiento de la sociedad industrial de masas, sino que él mismo se situó en el núcleo del campo de batalla político de la Alemania posterior a la Primera Guerra Mundial, de la nueva constitución, de la revolución fallida en 1923... y, posteriormente, de la emergente industria cultural norteamericana.

Si antes Eisler habia combatido la idea de que la autonomía artística en pro de la lucha directa participativa en los procesos históricos, la nueva situación del exilio le vio abocarse a una autonomía forzada, en buena medida puesta de relieve mediante el retorno al dodecafonismo aprendido de joven, y rechazado en el período político.

\section{La PRODUCCIÓN artística en UN PERÍOdo DE LUCHA}

La izquierda con la que se identificaba Eisler había sufrido muchos varapalos desde la fallida revolución de 1918- 
1919 [esa izquierda a la izquierda del SPD -es decir el USPD (partido de trabajadores antibélico), del que luego surgiria la Liga Espartaquista, y el Partido Comunista-]. Sus objetivos políticos habian sido lograr que Alemania siguiera los pasos revolucionarios de la Rusia Soviética y que el poder político fuese transferido sin excepciones a los consejos de trabajadores. A estas demandas, la izquierda moderada, las clases medias y los social-demócratas habian respondido con una fuerte ofensiva de alianza con los viejos estandartes de poder (burocracias, empresas y cuerpos de oficiales), lo que a muchos, incluso dentro de la socialdemocracia, dejó muy insatisfechos. Pero esa política de alianzas fue lo que en definitiva constituyó la república. Tampoco era el USPD un partido muy unido, con diferentes interpretaciones de cómo había que entender el proceso revolucionario y la estrategia de orden. Tras el putsch de Kapp los comunistas surgieron con algo más de fuerza e incluso defendieron posiciones militares frente a los Freikorps anticomunistas. Pero la división interna, que en ese momento se plasmó en si unirse o no a la Internacional Comunista (Commitern) de 1919 y seguir los dictados de Moscú, volvió a debilitar su resistencia. Los más a la derecha se acabarian uniendo al SPD en 1922. Otra ofensiva vino esta vez en 1921 por parte del KPD iniciando una rebelión en unas importantes zonas industriales con la intención de que la revolución acabase con el sistema parlamentario. La derrota no significó, no obstante, la desintegración de sus fuerzas, pero sí la peligrosa prohibición de las organizaciones extremistas. Las de izquierdas, pero no las de derechas, puesto que el sistema judicial estaba claramente escorado a la derecha. El KPD no volvió a levantar cabeza después de otro fallido intento revolucionario, esta vez en Alemania Central, bajo la rúbrica del "Frente Unido", que supuso con la subsiguiente declaración del estado de emergencia en defensa de la república. A partir de entonces, todos los golpes a partir de ahora provendrian de la extrema derecha. El período de "relativa estabilización" de 1924-30 terminó sin soportar la crisis económica de 1929 (el colapso de la Bolsa de Nueva York) y que, sumada a la crisis política, pudo ser aprovechada por el Partido Nazi para su atracción de las masas.

El definitivo golpe nazi a los movimientos de trabajadores tuvo lugar en 1933, año en que todas las organizaciones de izquierdas fueron prohibidas. Con el golpe llegó el final de la "música para la lucha" por lo que la música de Eisler, que había escapado de Alemania en 1932, un poco después que Brecht, empezaría a ser catalogada como arte que había que eliminar por completo. Así, por ejemplo, en la exposición de música degenerada de Düsseldorf figuraba "La canción de la solidaridad", que había compuesto para Brecht, y en el "Lexicon de Judíos en la música", compilado en 1940, su nombre aparecia bajo la rúbrica de compositor y agitador político, y junto a él la letra $\mathrm{H}$ de Halbjude. En Alemania, ni una sola nota de Hanns Eisler se oiría durante los doce años posteriores al golpe nazi.

Hanns Eisler había estudiado en Viena con Arnold Schönberg técnica dodecafónica. De su maestro aprendió, diría en sus palabras, la meticulosidad, la experimentación, la evasión de los lugares comunes, y la búsqueda del "ser musical de las obras maestras". Características sin duda reconocibles en la música de Eisler, y a las que habría que añadir, ya desde sus inicios, su meticuloso afán por la precisión, la concisión expositiva, la sencillez en las formas y la obsesión por lo concreto (rasgos también válidos para la escritura de Brecht). Él mismo reconocería, ya en su época de madurez, que el que su padre fuera filósofo y su madre obrera significó para él la pronta realización de un conflicto social que él catalizaría en forma de una dialéctica entre clases sociales, y que se llegaría a plasmar en su música en tanto que combinación justa de claridad y energía, de rigurosidad y decisión. En esta línea interpretativa, un comentario muy minucioso a la Sonata op. 1, ganadora del Premio de las Artes otorgado por la Ciudad de Viena, una pieza cromática, elegante, de ricas armonías y bastante densa, decía asi: "Hanns Eisler es el compositor representativo de la más reciente generación de alumnos de Arnold Schönberg... [A continuación se elogiaba la unión de agilidad y disciplina, así como la riqueza de las relaciones]... Eisler se manifiesta con una libertad que, deudora de Mozart, le permite hilvanar nuevo sobre nuevo $y$, sin embargo, crear una unidad. [Al final se insistía] en ese talento de Eisler para la Fantasía, que es su cualidad más propia sin hacerse tan evidentemente visible como su fuerza de invención melódica, la honradez armónica y el conocimiento instrumental" (Betz, 1994, 36). El comentario es de un jovencísimo discípulo de Alban Berg: Theodor Wiesengrund Adorno. El mismo Arnold Schönberg recomendó a su editor la publicación de esta pieza, brillante combinación de Prokofiev y dodecafonía, llena de sentido del humor, donde Eisler ya muestra a las claras su elegante destreza en los incidentes y rica armonía. 
Su peculiar técnica, en lo que se refiere a la música vocal, empezaba ya a vislumbrarse, y es la que caracterizaría a grandes rasgos toda su obra: Eisler tomaba unos textos como material -por ejemplo, para una de sus composiciones de transición, compuesta todavía en Viena, sobre las Zeitgedichten (op. 10) escritas por Heinrich Heine antes y después de la fracasada revolución de 1848- y los utilizaba, o más bien (como él diria) los hacía útiles, montándolos y remontándolos, dándoles un nuevo título, introduciendo líneas y cortes e incluso añadiendo otros textos. No se trataba de inventar una nueva técnica musical, sino de, mediante el montaje, articular o expresar musicalmente la función de la música en la sociedad, interrogándose sobre los cambios sociales y el modo en que éstos afectaban a la propia música. Eisler ponía así de manifiesto que los avances musicales aprendidos en Viena tenían que conservarse, pero dándoles un impulso social, y esto principalmente de la mano de textos que pusieran la música al servicio de los proletarios. En la apropiación de los poemas de Heine, los coros ridiculizaban los típicos coros de orfeones, pero al tiempo que lo hacian, invitaban asimismo a una lucha más intensa en el futuro, en lugar de un languidecer por el fracaso de la revolución de 1848. Este estilo sería el germen de esa Kampfmusik, o música de lucha, que seguiría en los años posteriores. La pieza fue escrita en 1925, más o menos cuando Paul von Hindenburg llegaba a ser presidente de la República, declaraba su poca simpatía hacia los socialistas, incluso cuando éstos eran moderados, y acto seguido empezaba a ejercer su influencia directa en la formación del gobierno, mayor de la que la constitución le otorgaba. A saber, el DNVP (Deutschnationale Volkspartei, unión nacionalista y pro-Kaiser de partidos conservadores, representantes de clases medias -algunos de ellos antisemitas) debería ser incluido en el gobierno, y el SPD debería ser excluido a toda costa. (Por su parte, el KPD había perdido casi toda su fuerza ofensiva tras las crisis de 1923 y el consiguiente estado de emergencia.) Hindeburg con ello se arrogaba derechos presidenciales que presagiarian lo que ocurriría en los años venideros.

Tras los estudios en Viena, que finalizó no sin un conflicto con el maestro debido a un comentario indiscreto del alumno (aunque Schönberg no podria haber entendido la función socialista que su discípulo quería dar a la música, ni Eisler se sentía motivado en continuar con la música moderna), Eisler se trasladó a Berlín, donde empezaba a compaginar su actividad musical -impartiendo clases en el conservatorio Klindworth-Scharwenka- con la teórica mediante la publicación de artículos sobre la función social de la música en el periódico comunista Die rote Fahne (La bandera roja), y donde iniciaría su crítica al l'art pour l'art y su intrépida conversión a una música que fuera claramente social y políticamente útil, a un idioma que pudiese llegar a las masas. Lo primero que la caracterizaba era su renuncia total a la autonomía, y la sustitución de esta aspiración por una "música aplicada", de manera que, como el mismo Eisler estipulaba, belleza, armonía y otras cualidades estéticas se pusieran al servicio de una causa política. Así lo ponen de manifiesto sus composiciones para coros de trabajadores -contrapunto político a los coros de diversa índole de escuelas o agrupaciones que ensalzaban sentimentalmente tradiciones y formas de vida comunales precapitalistas, y que con una facilidad pasmosa se habrian de convertir en cuestión de meses en abanderados de las reconstrucciones idílicas de lo ario en la ideología nazi. Por su parte, las ya mencionadas canciones de lucha, nacidas un poco más tarde que los coros, a partir de la gran crisis económica de 1929-30, y pensadas sin más como intervenciones directas, en manifestaciones o asambleas, habian de ser concisas, económicas y enérgicas, con una buena dosis de agitación, sin sentimentalismo de ningún tipo. El montaje de elementos de marcha con otros de jazz, de síncopas y bajos, generaba un brío sorprendente desde el primer momento - pero su sencillez, el que fueran compuestas en el modo menor era sólo aparente-. En la "Canción de la solidaridad", por ejemplo, la asimetría de la línea melódica y el cambio de compás provocaba contrastes y hacía avanzar a marchas el texto, que se insertaba como en una especie de camino difícil por el que se tenía que transitar con fuerza, decisión y audacia. Las letras se tenían de entender fácilmente, pero sin que el texto atrapase a la audiencia, renunciando por tanto a la empatía, y apuntando a la misma dificultad de la ejecución. La energía que la rodeaba estaba, sin embargo, a años luz de la afirmación de poder de las marchas fascistas que pocos años más tarde resonarían por toda Alemania.

Las observaciones de Walter Benjamin sobre el teatro politico de aquellos años en Alemania ponen de relieve que el campo de batalla de la izquierda artística estaba ocupado por posiciones muy distantes entre sí, y que pocas, según Benjamin, estaban bien definidas, por tanto, tampoco a la altura de las circunstancias, que él vislumbraba como revolucionarias. A su juicio, el teatro político no debía 
contentarse con insertar a las masas proletarias en posiciones creadas por el aparato teatral para la burguesía, sino que debía transformar el contexto social mismo en el que se hacía ese teatro. De ahí las feroces críticas a quienes formaban parte de lo que él Ilamaba "melancolía de izquierda" (y aquí estaban incluidos la Neue Sachlichkeit y el expresionismo) porque simplemente se limitaban a lamentarse en una autocomplacencia de lo negativo, con la consecuencia fundamental de que acababan vendiendo sus esfuerzos a la burguesia: "su significado político se agotó con la transformación de los reflejos políticos, en cuanto que éstos emergieron en la burguesía, en asuntos de distracción y de diversión que se suministraban para el consumo" (Benjamin, 1991, 279-283). Pocos se salvaron de la fuerte polémica iniciada por Benjamin. En El autor como productor, sin embargo, ponía como ejemplo de práctica artística proletaria a Hanns Eisler: éste y sus colaboradores intentaban trascender la especialización en el proceso de producción intelectual, y de esta manera intentaban romper o cruzar las barreras que dividian el trabajo conjunto de las fuerzas productivas. Sólo así, sostenía Benjamin, podían descubrir los autores que eran productores en solidaridad con otros productores y con otros trabajadores, con los que de otra manera apenas entrarían en contacto. $Y$ citaba a Eisler: "También en la evolución de la música, tanto en la producción como en la reproducción, tenemos que aprender a percatarnos de un proceso de racionalización cada vez más fuerte... El disco, el cine sonoro, los aparatos, pueden distribuir ejecuciones musicales refinadas... en forma de conserva como mercancía. Este proceso racionalizador tiene como consecuencia que la reproducción musical se haya limitado a un grupo de especialistas cada vez más pequeño, pero también mejor cualificado. La crisis de la práctica de los conciertos es la crisis de una forma de producción anticuada, superada por nuevos inventos técnicos" (Benjamin, 1998, 127). Eran tesis similares a las del célebre texto sobre "La obra de arte en la época de la reproductibilidad técnica" y resumian la tarea que Benjamin y Eisler encomendaban al arte, el cual era alzado como alegoría esencial de las formas de productividad contemporáneas. El arte había de instar a la creación de formas de colectividad y de praxis colectiva en las que los medios de producción, los objetos y las relaciones sociales fueran efectivamente apropiados por los sujetos involucrados en ellas. Y esto sólo sería posible si aquellos que habian recibido la educación suficiente en el seno de las clases medias creaban lazos de solidaridad con los que no la poseían, pero no en la forma de una supuesta proletarización, que no eliminaba en sí el privilegio del que se partía, sino mediante la politización explícita en el arte o en los escritos. (Véase por ejemplo su reseña de S. Krakauer, Die Angestellten: Aus dem neuesten Deutschland, aparecido en Die Gesellschaft, 1930) (Benja$\min , 1991,219-225)$.

El equipo Brecht-Eisler se caracterizaría desde un primer momento, y durante los dos años previos al exilio, por un intento de sacar el máximo partido a los medios artísticos burgueses, pero para darles una nueva función política. Sobre el cambio experimentado por Eisler tras su abandono de la escuela de Schönberg escribía sin embargo Adorno: "En tanto que esta música surge del frente de la acción inmediata, lo refleja, y se establece como forma artística, evidente que las formas producidas no resisten frente a la avanzada producción burguesa [...] Sin cesar cobra atención, el que la escuela de Schönberg, de la que proviene la figura del hasta ahora el más consecuente compositor proletario Eisler, esté en contacto con esfuerzos que aparentemente le son contrarios y se oponen a ella. Para que este contacto fuera fructífero, su uso debería encontrar una dialéctica: no debería dirigir la música pasiva y unilateralmente tras la conciencia de los que la usan, sean proletarios o no, sino más bien intervenir activamente él mismo con su forma en la conciencia" (Schebera, 1998, 89). Pero en estos conflictivos años de la República de Weimar, Eisler no pretendía ya avanzar tanto en los desarrollos técnicos de la música burguesa, tampoco quedarse en la mera defensa de posiciones, sino en movilizar a los trabajadores para la lucha. Habría que añadir, sin embargo, que trabajos que con posterioridad compondría durante el exilio serían buena muestra del esfuerzo que Adorno le estaba recomendando. No obstante, tal vez Adorno no llegó a entender que en las composiciones de Eisler de aquellos años sí había una relación dialéctica, muy sutil, entre la música y las letras, entre la música diatónica y la claridad de sus estructura.

Hacia finales de octubre de 1932, la batalla política de Eisler se encuentra en su punto álgido. Junto con Brecht compone para Helene Weigel "Vier Wiegenlieder für Arbeitmütter" (Cuatro canciones de cuna para madres trabajadoras), una pieza energética a la vez que melódica y sencilla. También sería de este año "O Fallada, da du hangest" (Fallada, mientras cuelgas), una de las más emocionantes composiciones de protesta contra la creciente 
miseria y deformación física de los hombres cuando están sometidos a la más terrible penuria económica. Todas esta piezas utilizaban las notas del modelo de escalas frigio, sobre las que trabajaba con el estilo compositivo que había aprendido de Schönberg, y a partir de ahí formaba muchas variaciones sencillas que podian ser percibidas en la ejecución en relación unas con otras. Brecht decía de las composiciones de Eisler que eran "bastante complicadas" - y es que estaban llenas de sutileza e inteligencia, a pesar de la apariencia de sencillez e inmediatez, de frescura y ligereza, de colorido y brusquedad, con la que las percibimos a primera vista. Las últimas composiciones breves de Eisler en colaboración con Brecht antes del exilio fueron "Der Marsch ins Dritte Reich" (La marcha en el Tercer Reich), y dos semanas antes del inicio de la dictadura de Hitler, la canción "Spartakus 1919", con una letra que no sólo recordaba los asesinatos de Kart Liebkneckt y Rosa Luxemburg, sino que habría de ser profecía de lo que iba a ocurrir: "O Spreeathen, Oh, wieviel Blut hast du gesehn" (O Spreeathen, cuánta sangre has visto).

\section{Quince años en el exilio: una aUtonomía FORZADA}

Las piezas recopiladas en "Lieder und Cantaten im Exil" fueron compuestas a partir de un momento de crisis en la vida de Eisler, un poco después del inicio de gestación de la sombría y deprimente "Deutsche Sinfonie" (Sinfonía alemana), que iniciaría en 1936 y terminaría en 1939, ya en Estados Unidos, cuando Hitler y Stalin firmaban el pacto de no agresión, y como una secuencia de cantatas y movimientos instrumentales antifascistas. Durante el largo período de exilio, Eisler viajaría por la Unión Soviética, Dinamarca (con Brecht), en España con las Brigadas Internacionales, en Nueva York, y finalmente en Hollywood, con la gran colonia de exiliados alemanes (Thomas Mann, Alfred Döblin, Lion Feuchtwanger, Adorno, Schönberg...). Se podría decir que hasta más o menos el año 1937 Eisler todavía confiaba en que Hitler iba a durar poco en el poder, $y$ en que era posible animar a las masas a movilizarse contra el régimen, y a que los trabajadores extranjeros se solidarizasen con sus compañeros alemanes. A partir de la llegada de los exiliados alemanes a Estados Unidos hacia 1931 había surgido la primera "Workers Music League" (Liga de trabajadores para la música), para la que Eisler se había convertido enseguida en figura clave; también en 1932 aparecieron traducidas todas sus canciones de lucha. Otra importante pieza combativa, la música para Cabezas redondas y cabezas puntiagudas, había sido compuesta en Dinamarca en 1934, así como la "Canción para el frente unido". Eisler viajó a España el 10 enero 1937, donde se encontró con Ernst Busch y donde compondrá dos canciones, "Marcha del 5. regimiento" y "No pasarán", con letras de José Herrera Petere. Posteriormente se acercaría hasta Murcia para visitar la XI Brigada Internacional.

Pero hacia 1937 el régimen hitleriano se había asentado ya con firmeza en Alemania y empezaba a ser apoyado por un cada vez mayor número de alemanes. La apresurada reconstrucción de la Wehrmacht (fuerzas armadas), realizada desde 1935, hacía cada vez más claro que Alemania tenía intenciones expansivas muy ambiciosas. Eisler y Brecht se dan cuenta de que su regreso tendrá que hacerse esperar mucho tiempo. Del año 1937 son el "Réquiem de Lenin" y las "Cantatas de Cámara", así como las "Zwei Elegien" (Dos Elegías), con textos de Brecht. En estas composiciones empieza Eisler a desarrollar un proyecto de dialéctica entre la tradición y la vanguardia, de manera que la música dodecafónica se pueda emplear productivamente para expresar de una manera sencilla y directa la nueva situación política. En la segunda, en sus líneas más célebres, se refleja el ya largo período de exilio: "Cambiábamos de país como de zapatos ¿a través de las guerras de clases, y nos desesperábamos? donde sólo había injusticia y nadie se alzaba contra ella". La melodía y el acompañamiento del piano en las elegías, en técnica dodecafónica muy libre, están dominados por un tono pensativo, pero no triste, por medio del cual Eisler persigue combinar la claridad expositiva con un contenido político determinado. El desorden del que hablan las letras no es un caos originario, un estado de naturaleza en el que todos luchan contra todos, sino un caos que pertenece a un tiempo concreto, que puede ser señalado en sus orígenes y causas. La vida en un lugar así es transitoria y consiste en una lucha continua, pero se trata, de nuevo, de una vida situada en un tiempo de miseria, pero cambiable, pues se vislumbra una meta, hoy por hoy inalcanzable, pero no por ello inexistente. De momento, en esta situación, el poeta sabe, por lo menos, que "Los poderosos se sentían más tranquilos sin mí". Hay un tiempo futuro, unos hombres venideros, y el poeta dirige sus palabras a ellos, de nuevo apuntando a la posibilidad de la transformación de lo presente. Les 
incita a que recuerden los tiempos sombríos de los que se han librado, que han superado, que los tengan presentes en su memoria: los tiempos en que reinaba la injusticia y la desesperación. En tiempos sombríos la amabilidad no es posible, y el odio contra la bajeza afecta también a quienes lo experimentan: el poeta concluye pidiendo a los hombres venideros que sean indulgentes para con nosotros. Las canciones se han de interpretar sin emoción, sin dejarse llevar por la densidad del texto. El texto se tiene que captar en su inmediatez, casi como si fuera un texto hablado al que se le da un tono ligeramente melódico. Sólo así se expresa la dialéctica del distanciamiento en la ejecución misma de la pieza. Otra canción del mismo año es "Der Pflaumenbaum" (El ciruelo), en este caso una canción para niños basada en el poema de Brecht que también Walter Benjamin comentaría.

En 1938 se instalaba ya definitivamente en Estados Unidos, donde se convertiría en profesor de composición y contrapunto en la New School for Social Research de Nueva York, que había creado en 1933 una sección denominada "Universidad en el exilio". (Otros compositores que emigraron a distintas instituciones norteamericanas fueron Arnold Schönberg en el Malkin Conservatory de Boston y más tarde en la University of Southern California en Los Ángeles, Paul Hindemith en la Yale University, Ernst Toch, también en la New School for Social Research, Ernst Krenek en el Black Mountain College de North Carolina y en el Vassar College de Nueva York; Otto Klemperer, que fue a la Los Angeles Philarmonic Orchestra, Bruno Walter, director de varias orquestas, George Szell, director de la Metropolitan Opera y del Opera Workshop de la New School). Aparte de ganarse la vida dando clases de composición y contrapunto en la New School, Eisler formaba parte de grupos politicos, como el "Composers' Forum Laboratory", financiado con fondos del New Deal de Roosevelt, colaboraba en varios grupos de música de trabajadores, y se dedicaba a componer música para películas, por ejemplo: "The 400 Million", documental dirigido por Joris Ivens en 1939, que sería la primera película para la que emplea la técnica dodecafónica. También sería decisivo el encuentro con el director Joseph Losey, que luego adaptaría el Galileo de Brecht. La primera colaboración Eisler-Losey tuvo lugar en 1939, para la película Pete Roleum and His Cousins (Pete Roleum y sus primos), donde figuran las célebres canciones "We're pouncing on the Oil" y "Bucket Song", sobre quien escribiría el célebre pianista Oscar Levant que eran lige- ras, claras de ideas, así como precisas en la orquestación, brillantes y sutiles.

La situación como exiliado sin embargo no era fácil: Eisler padecía crónicamente de falta de dinero y tuvo problemas con el visado y el permiso de residencia, a pesar de que había solicitado uno largo. Las autoridades empezaban a tomar nota de sus actividades políticas debido a su cercanía con la liga de trabajadores para la música, y al partido comunista. El 21 de agosto de 1939 iniciaría el trabajo de la música para la canciones "Gedanken über die Dauer des Exils" (Meditaciones sobre la duración del exilio) sobre poemas de Brecht, cuando era profesor invitado en el Conservatorio de Música de la Ciudad de México, así como de la primera parte de "A los hombres venideros", y para el soneto número 66 de Shakespeare. En las primeras Brecht y Eisler muestran el carácter transitorio de la existencia en el exilio, en la que la temporalidad se acelera, pues nunca se sabe dónde se estará el día siguiente. Las preocupaciones del día a día empequeñecen en comparación con lo que se dejó, puesto que la duración del exilio afecta cada instante, dándole una intensidad distinta a la habitual. Pero tampoco las pequeñas alegrías (como regar un árbol) le son permitidas al exiliado, el conocer gente, el aprender el idioma, porque su vida está encauzada a un único instante: al regreso. Ésa es la esperanza que le mantiene con vida, que da sostén a su trabajo: la ilusión de que la injusticia cometida será vencida. Pero a pesar de la desgracia, hay que regar el árbol. La música de Eisler no ilustra ni expresa sentimientos, sino que los comenta, deja que el texto se muestre en un primer plano, para que se entienda, pero sin rastro de efusividad en la ejecución, sin posibles identificaciones, para que el oyente pueda apropiárselo activamente y con un esfuerzo intelectual. Por su parte, la canción sobre el soneto de Shakespeare, que se inicia con "Tired of all this", fue escogido por Eisler en el momento en que su situación política en Estados Unidos se le estaba complicando muchísimo, pues las autoridades norteamericanas no sólo no le concedieron el visado adecuado, sino que además le llegó una orden de arresto justa -y supuestamente- a causa del visado que no llegaba, y tras un viaje desde México que le trajo consigo una espera en la frontera de un mes largo, debido a que su nombre estaba en una lista negra. Por esas mismas fechas Hitler y Stalin firmaban el ya mencionado pacto de no agresión (23 agosto 1939), que causaba 
estupor al mundo entero, y al poco tiempo Hitler invadía Polonia y se iniciaba la Segunda Guerra Mundial.

En 1940 recibiría una beca para estudiar la función de la música en el cine. De esta labor resultarian partituras para cuatro películas y el libro, escrito junto con Adorno, Composing for the films (Adorno y Eisler, 1994). En este libro Adorno contribuyó sobre todo con sus reflexiones sobre la industria cultural, en particular sobre las ilusiones de inmediatez generadas por las películas de Hollywood. Ambos dedicaron su crítica a los distintos elementos característicos de las bandas sonoras: por ejemplo, las fáciles melodías, que tienen que permanecer inconscientes, la mímica de lo visual, la música enlatada, los clichés, etc. La impronta particular de Eisler se nota en las reflexiones sobre el uso de instrumentos, sobre el papel del compositor en su recurso a la de-familiarización. Composing for the films no deja de ser, sin embargo, un híbrido que no llega a disimular a veces las ideas contrapuestas de sus dos autores.

El último traslado dentro de los Estados Unidos tiene lugar en 1942. Eisler se mudaría a California, seguramente porque su amigo Brecht llevaba ya un año allí, algo que éste último había logrado no sin muchas odiseas por diversos países. (Escapó de Dinamarca poco antes de la llegada de la Wehrmacht, y luego tuvo que salir de Moscú en el transiberiano, habiendo pasando antes por Finlandia, y dejando atrás sin remedio a su colaboradora Margarete Steffin, que moriría de tuberculosis. Un barco le Ilevaría a Manila, y de ahí a California). La situación de los exiliados durante este período tampoco sería nada fácil, simplemente recordar que tenían que registrarse como "Enemy aliens" ("extranjeros enemigos") y que sus vidas estaban sometidas a controles insoportables. En Santa Monica, Eisler y Brecht empezaron a reunirse casi a diario, vivian a veinte minutos en coche. Cada uno tenía que ganar dinero, cada uno por su lado, en el mercado de Hollywood, como diría Brecht. Ninguna de las composiciones que Eisler realizó para los estudios ["Hangmen Also Die" de Fritz Lang (1943), "None But the Lonely Hearts" de Clifford Odets (1944), "The Spanish Main" de Franz Borzage (1945), y otras con Gustav Machate y Douglas Sirk entre otros] le resultaría un trabajo del que sintiera satisfecho. El libro que escribió junto a Adorno le serviría para desquitarse de la mala experiencia: criticaría la incompetencia de los departamentos de música de Hollywood, el bajo estatus otorgado al compositor, la estructura rígida de las orquestas. Es por este tiempo también cuando Eisler se aproximaría a su maestro Schönberg, quien también estaba sufriendo en los estudios de Hollywood.

Eisler recordaría un día especial en que Brecht se acercó a su casa: "Me dio un sobre con unos veinte poemas y me dijo: 'mira, tal vez haya aquí algo que puedas usar'. Es decir, lo había concebido como propuesta para composiciones. (...) Lo miré, y le dije, 'Brecht, esto es colosal', a lo que preguntó, '¿de verdad? ¿Te parece utilizable?' Brecht nunca decía nada más. 'Brauchbar': ésa fue su formulación. Lo compuse inmediatamente y se lo toqué. Estaba muy de acuerdo" (Schebera, 1998, 180-1). Éste sería el inicio de una de las más impresionantes desarrollos musicales del siglo XX, la colección de 49 canciones Hollywood, conocida habitualmente por el título de "Hollywood Liederbuch". A pesar de que el contexto era muy distinto, Estados Unidos acaba de meterse en guerra y Alemania seguía al frente de su expansión fascista, Brecht y Eisler seguían confiando en la función social del arte. Ya no se trataría, no obstante, de un activismo militante, sino más bien de la posibilidad de una vuelta a Alemania poshitleriana, en la que ambos siguieron creyendo hasta el final. Se dedicarian por ello a rescatar del pasado una tradición alemana opuesta al fascismo, y a crear un arte que sirviera a los futuros alemanes para reconocerse a sí mismos en otra cosa que el nazismo. $Y$, en particular, les pareció importante recobrar la tradición de los Lieder acompañados al piano (Beethoven, Schubert, Schumann, Hugo Wolf) como contraposición a las canciones nacional-socialistas. En particular, el "Hollywood Liederbuch" contiene tanto reflexiones sobre la situación de los exiliados y la guerra mundial como recuperaciones de textos clásicos alemanes que se afirman como críticas a todo lo que Hollywood representa. Las canciones dedicadas al exilio están escritas en una atonalidad libre, la voz domina en un primer plano, y el acompañamiento del piano se limita a un segundo plano de apuntalamiento o acentuación de los momentos importantes. Pero ninguna de estas canciones están destinadas a la inmediatez de la lucha; son, más bien, observaciones distantes desde un mundo con el que no coinciden, como expresaria Brecha en su Diario de Trabajo: "Escribir aqui lírica, incluso actual, significa: retirarse a la torre de marfil. Es como dedicarse al arte de la orfebrería. Esto tiene algo de extravagante, estrafalario, torpe. Tal lírica es como arrojar una botella al mar" (Betz, 1994,180). La música de Eisler adquiere distancia, deja que las letras pasen a un 
primer plano y se puedan experimentar conscientemente, toma elementos musicales de distintas tradiciones y los monta entre sí en una amalgama fascinante (desde las viejas canciones de lucha, hasta el jazz y el Lied clásico). Lo interesante de estas composiciones es que, al volver a la tradición de los Lieder, por medio de ellas, Eisler recoge el subjetivismo característico de esta tradición, pero lo desfamiliariza, rompiendo cualquier posibilidad de identificación por parte de la audiencia, mediante la introducción de vacíos y elementos paródicos, de recursos musicales y de imágenes destructoras de la melancolía característica de esa tradición. $Y$ es aquí, finalmente, donde el exilio político de Eisler y Brecht se podría convertir en condición contemporánea por antonomasia: se trata del exilio social y político de los individuos que no controlan el destino de sus vidas porque otras fuerzas mayores lo hacen por ellos, de la resistencia frente a la asimilación por parte del mercado. Así, Eisler: "En esta melancólica, eterna primavera de Hollywood le dije a Brecht poco después de que nos hubiéramos encontrado [...] 'Éste es el clásico lugar donde uno tiene que escribir elegías [...]. No se está impunemente en Hollywood. Sencillamente, hay que describirlo [...].' Éste era el terrible idilio de este paisaje, que en sí procede ante todo del cerebro que rige la especulación del suelo [...] Si se suprimiera allí tres días el agua, volverían a aparecer los chacales y la arena del desierto [...] Así, en este extraño y enlucido idilio, una ha de expresarse también concisamente" (Betz, 1994, 181). El individuo está exiliado de lo que le rodea, falto de identificaciones para con su condición social, porque lo que le rodea, el mundo en su conjunto, pertenece a unos pocos, porque la ciudad y el paisaje han sido concebidos para el entretenimiento y la mentira, como paraísos artificiales entre los que florece el dinero. Se trata de una situación desesperada, pero que no puede hacer caer al artista en la mera pasividad: de ahí que el cantante tampoco pueda dejarse llevar por el sollozo, por el sentimentalismo, sino que tiene que invocar, en su ejecución, la no naturaleza de esta condición de exiliado, la no resignación ante lo dado. En medio de la industria cinematográfica, el regreso a los Lieder no es un regreso a un tiempo mejor, a un romanticismo de las formas por medio de las cuales el sujeto expresa su más íntimo ser, sino, por el contrario, a una expresividad que dialectice la situación actual, que exprese la no identificación del sujeto con su entorno, que lo muestre en su contingencia, en su finitud, en su posible transformación.

En 1947 Eisler y Brecht fueron Ilevados ante el Comité de Actividades Norteamericanas. Eisler nunca formó parte del Partido Comunista, pero tampoco ocultó su afiliación política. Fue interrogado sobre Die Massnahme, así como por la canción "Lob des Kommunismus" en La madre, y por ser el hermano del espía comunista Gerhart Eisler (periodista político muy conocido). El presidente del comité de interrogaciones, Parnell Thomas, declararía que su propósito fue era "mostrar que el Sr. Eisler era el Karl Marx del comunismo en el campo de la música, y además es consciente de ello". Eisler le respondió que se sentiría muy halagado por una comparación así. Se montó una protesta a cuya cabeza se encontraban Chaplin, Thomas Mann, Einstein, Picasso, Copland, Matisse y Cocteau (Adorno retiró su nombre de Composing for the films), pero que sólo sirvió para ser liberado y, al poco, expulsado de los Estados Unidos, en 1948.

\section{BIBLIOGRAFÍA}

Adorno, Theodor y Eisler, Hanns (1994): Composing for the Films, Atlantic Highlands, NJ, Athlone Press.

Benjamin, Walter (1991): GesammelteSchriften Band III, Frankfurt, Suhrkamp.

Recibido: 26 de marzo de 2008 Aceptado: 23 de abril de 2009
- $\quad$ (1998): Tentativas sobre Brecht, trad. Jesús Aguirre, Madrid, Taurus.
Betz, Albrecht (1994): Música de un tiempo que está haciéndose a sí mismo, trad. Ángel-Fernando Royo, Madrid, Tecnos.

Schebera, Jürgen (1998): Eisler. Eine Biographie in Texten, Bildern und Dokumenten, Mainz, Schott.

doi: 10.3989/arbor.2009.739n1062 